\title{
THE ENGLISH-LEARNING STRATEGIES OF AN INDIGENOUS ENGLISH LEARNER IN THE NORTHEAST OF THAILAND
}

\author{
Vincentia Aprilla Putri \\ Graduate Program in ELT, Faculty of Letters, Universitas Negeri Malang, Indonesia \\ E-mail: vincentiaaprillaputri@gmail.com
}

APA Citation: Putri, V. A. (2020). The English-learning strategies of an indigenous English learner in the northeast of Thailand. Indonesian EFL Journal, 6(1), 11-18. doi: 10.25134/ieflj.v6i1.2633.

\begin{abstract}
This study investigated English-learning strategies applied by an indigenous student in Amnat Charoen Province, in the Northeast of Thailand. Despite the lack of English exposure in the area, the participant, who was an English learner at a private primary school in Amnat Charoen Province, Thailand, had an excellent English ability. The data collection and analysis were done qualitatively through interviews and observations. Based on the interviews and observations, the participant was reported using both direct and indirect strategies in learning English. The dominant direct learning strategies were memory strategies and compensation strategies. The participant developed habits to summarize learning materials and use gestures to assist the speaking practice. Also, in the frame of indirect strategies, the participant applied social strategies more frequently than other indirect learning strategies. The social strategies were obviously noticeable in the consistency to practice English by interacting with foreign teachers. Further, the social learning strategies were also believed to be the most essential learning strategies developed by the participant.
\end{abstract}

Keywords: learning strategies; direct strategies; indirect strategies.

\section{INTRODUCTION}

Individuals do not use the same way to learn (Seel, 2012). In order to give explanations of individual learning differences, experts introduced the notion of learning strategies (Seel, 2012). Oxford (1990) as cited in Pawlak (2019), stated that strategies are specific actions taken by learners to make learning easier, faster, more enjoyable, more self-directed and more transferable to novel situations. Hence, each individual who has developed learning strategies can enhance their autonomy in mastering the target language. Meanwhile, recently Griffiths (2018) as cited in Pawlak (2019) defined language learning strategies as actions chosen by learners for the purpose of language learning.

Research on learning strategies revealed that good language learners benefited from some language learning strategies, especially in terms of proficiency levels. Most studies on language learning strategies confirm that successful learners use more strategies than unsuccessful learners. Besides, successful learners frequently use the strategies that help them become successful (Qingquan, Chatupote, \& Teo, 2008; Lai, 2009; Rao, 2012; Oxford, 2017). Similarly, another study conducted by Dmitrenko (2017) identified strategies used by multilingual learners who were learning additional languages. They were aged 18 onwards, and have different academic and professional backgrounds and stemming from intermediate or higher socioeconomic environments. All of them had Spanish as their first or second language, and they learned a European language with a Latin-based writing system. The study revealed that almost all the strategies listed in the questionnaire based on the framework of the learning strategies by Oxford (1990) were reported to be applied frequently by multilingual learners.

Since studies have shown that learning strategies are rigorously related to successful learners, having more considerations on students' learning strategies will be undoubtedly beneficial. This point of view is in line with Bai \& Guo (2019) who specified that in relation to language teaching, the success of a language teaching depends, among others, on understanding students' learning strategies. In the school setting, for instance, when teachers have a good understanding of students' learning strategies, they will have a better implementation of instruction which are suitable for students to improve language learning.

Nevertheless, studies on language learning strategies have shown that there are various factors influencing individuals' English learning strategies, such as cultural background, national origin, and language teaching method (Nyikos, 1989 in Lai, 2009). Most studies revealed that students who come from different culture, nationality, and various schools are potentially 
different in the ways they approach learning. For instance, Mazumder (2014) investigated the motivation and strategies used by students in public and private universities in Bangladesh. The study used the Motivated Strategies for Learning Questionnaire (MSLQ) and revealed that there was no significant difference between public and private universities in Bangladesh in most of the categories. After that, the result was compared to two other results from two countries, China and the USA. The comparison revealed some differences between Bangladesh, China, and the USA. The difference indicates that students from different geographical regions may learn differently.

Although previous studies have demonstrated the learning strategies of students from different countries, the majority of them were conducted among students with diverse backgrounds and learning experiences from the one who is going to be the participant of this study. Besides, most of the studies were conducted among a mixed group of learners from different countries, and there are very limited studies investigating the Englishlearning strategies used by students from monoculture and particular linguistic contexts, such as Thailand. Therefore, this study aims at investigating the English-learning strategies of a successful English-language learner in the Northeast of Thailand by answering the following research question: What are the English-learning strategies employed by a successful English-language learner from the northeast of Thailand?

English has been a part of the curriculum and becomes a compulsory subject from primary school onward in Thailand (Chamcharatsri, 2010). The presence of English subject in formal schools has been for around 150 years, since King Rama IV ordered that English be a part of the training for royal children (Watson, 1980 in Grubbs, Chaengploy, \& Worawong (2009). Thai people then consider English as a foreign language, which is mainly used for business, tourism, and educational purposes. Thus, students who want to get a good position in large corporations push themselves to learn and use English accurately and fluently. However, numerous Thai students still claim that English subject is monotonous and stressful. They do not even find reasons to learn English (Chamcharatsri, 2010).

A study conducted by Grubbs, Chaengploy, \& Worawong (2009) on students at three traditional university campuses and four
Rajabhat university campuses in Central-Western Thailand revealed that students had positive views on English. Most students thought English was important and beneficial for their academic pursuits. However, they did not think highly of their abilities. This point of view is in line with other studies that revealed the difficulty in English-learning among Thai students. The challenge in mastering English is shown by the English test results of Thai national testing, which got worse at least from 2000 to 2008 (Klainin, 2009). Further, it is surprising that among all regions in Thailand, the Northeast of Thailand (which is known as Isan and consists of twenty provinces) is ranked as the weakest region at English in Year 11 national testing (Draper, in press as cited in Draper, 2012).

The national language spoken by students undeniably influence the English proficiency of Thai students. The Thai language is somehow different from English in terms of phonological, grammatical, and lexical items. In terms of grammar, the Thai language does not apply the verb as a tense marker. It uses adverbs or nouns signifying time, which is placed in the sentenceinitial position. In the Thai language, the participant precedes the verb, the object follows the verb, forming Subject-Verb-Object word order without the presence of the semantic role of a noun phrase. Besides, in Thai language, verbs are not only to represent action and its objec-tives but also a cause and its result, and action and its evaluation. Moreover, causative and passive constructions are part of verb serialization (Minegishi, 2011). In terms of speech or expression, some speech events in Thai and English are different. For instance, in saying apology and thanks. In English, there are many ways to apologize, whereas Thai people would say sorry in a single form. Besides, when the British may have several direct strategies to express thanks, Thai people have less explicit strategies (Intachakra, 2004).

One of the best-known frameworks for concepts of English-learning strategies is the one launched by Oxford (1990). Oxford believes that language learning relies on two major learning strategies, namely, direct strategies and indirect strategies. Direct strategies contribute directly to learning, and indirect strategies contribute indirectly to learning. Direct strategies require mental processing of linguistic information. Meanwhile, indirect strategies support and manage language learning without directly involving the target language (Oxford, 1990 as cited in Ardasheva \& Tretter, 2013).

Direct strategies involve memory strategies, 
cognitive strategies, and compensation strategies. Memory strategies enable learners to store verbal materials and retrieve them for communication. In memory strategies, learners learn through acronyms, rhyming, images, the keyword method, body movement, mechanical means and location. They also do grouping and using context. Memory strategies are helpful for learners to memorize vocabulary and structures (Oxford, 1990 in Solak \& Cakir, 2015). Cognitive strategies involve the transformation of the new linguistic material to comprehension and production. These strategies include practicing, receiving, and sending messages, analyzing and reasoning, and creating a structure for input and output (Oxford, 1990 in Ardasheva $\&$ Tretter, 2013). In cognitive strategies, learners usually do analysis, note-taking, summarizing, synthesizing, outlining, and reorganizing information to reach their objectives (Oxford, 1990 in Solak \& Cakir, 2015). Lastly, compensation strategies enable learners to practice a new language for either comprehension or production despite limitations in knowledge. Compensation strategies involve guessing, asking for help, and using gestures (Oxford, 1990 in Ardasheva \& Tretter, 2013).

Meanwhile, indirect strategies involve metacognitive, affective, and social strategies. Metacognitive strategies enable learners to control their cognition and learning needs. For instance, learners have focus attention, planning, organizing, arranging, monitoring, and evaluating the learning process (Oxford, 1990 in Ardasheva \& Tretter, 2013). The metacognitive strategies are related to students' own regulation and monitoring of their vocabulary learning (Yaacob, et al. 2019). Affective strategies assist in regulating emotions, attitudes, motivation, and values. Students who employ these strategies can lower their anxiety and have selfencouragement (Oxford, 1996). Since these strategies are useful for dealing with interfering feelings, they are advantageous for beginner learners (Seker, 2015). However, learners do not need these strategies as they improve in proficiency (Oxford, 1996). Finally, social strategies facilitate students' interaction, social behaviour, and communication. Learners who use these strategies like to work with others, ask questions, ask for help and have the desire to learn about other cultures (Oxford, 1996).

\section{METHOD}

The participant of this study was a successful English-learner, namely Noi (pseudonym). The participant lived in a province in the Northeast of Thailand, namely Amnat Charoen. Amnat Charoen is part of Isan (regions in the northeast of Thailand, bordering Laos and Cambodia). Since Amnat Charoen is very close to Laos, people in Amnat Charoen, including the participant, speak Isan language (Thai language, which is still related to Lao). In terms of the tourism industry, Amnat Charoen has not been widely known by international tourists; thus, finding foreign tourists in Amnat Charoen is not as easy as finding tourists in Bangkok.

The participant was a ten-year-old primary-four student in a private elementary school in Amnat Charoen Province, in which the researcher taught English for two years from 2016 to 2018. At school, the participant learned English in three different subjects, namely Basic English, English for Communication, and Phonics. Although the school was not an international school, each of the three subjects was taught for two hours per week by teachers from Cameroon, Indonesia, and Thailand. The participant was special. Despite the fact that other Thai students faced many problems in learning English, the participant was considered to be a successful English learner by a number of teachers. The participant had excellent test scores in all of English subjects, and showed clear and excellent pronunciation in English. Therefore, the participant could communicate well with foreign teachers. Moreover, the participant showed high motivation and interest in English competitions held by schools and governments. As a result, the participant frequently won English competitions, such as storytelling, speech, and other projects, not only at school level but also in the province and national levels.

This research was conducted qualitatively. According to Creswell (2012), one of the characteristics of qualitative research is examining a problem and elaborating a detailed understanding of a central phenomenon. In this qualitative research, the researcher uses a case study as a method. As defined by Fraenkel (2012), a case study focuses on extensively studying single individual, group, or important example and collecting varied data to formulate interpretations which are applicable to the specific case or to provide useful generalizations. Therefore, the researcher tried to extensively explore the Englishlearning strategies of the indigenous student from the Northeast of Thailand, namely Noi (pseudonym). The investigation and analysis were done based on the theories which were related to English-learning strategies of individuals.

In this study, the research instruments used by 
the researcher were an interview guide and an observation form. The interviews aimed at discovering the English learning strategies possessed by the participant. Besides, to avoid response bias, the observations on the English learning strategies were also done. By using these two instruments, the research was expected to demonstrate trustworthiness,

The interviews were conducted in English and were done twice during the weekend on $17^{\text {th }}$ and $24^{\text {th }}$ February 2018. Meanwhile, the observations were completed every week in two months, from February to March 2018. The interviews covered questions related to the English-learning strategies possessed by the participant both inside and outside the school. At the same time, the observations focused on the English learning strategies maintained by the participant during the English classes. There are two big dimensions of English-learning strategies, namely direct and indirect strategies developed by Oxford (1990). The direct strategies consist of memory strategies, cognitive strategies, and compensation strategies. Meanwhile, indirect strategies cover metacognitive strategies, affective strategies, and social strategies.

Upon the completion of the data gathering, the researcher carried out the data analysis. The data obtained from the two instruments were transcribed, analyzed, and interpreted.

\section{RESULTS AND DISCUSSION}

Since both direct and indirect strategies contribute to the success of learning, digging out the use of both strategies on a successful English learner is necessary. Although most studies show that successful learners used more strategies than unsuccessful learners, the present study discovers that a successful English learner has shown dominant learning strategies that significantly contribute to her success. The analysis of the strategies possessed by the successful English learner promotes the awareness of the broad range of Englishlearning strategies options available to reach the same success. Besides, the understanding of students' learning strategies will help teachers to have a better implementation of instruction to improve students, especially since English is a compulsory subject for students at primary school onwards in Thailand.

Based on the interview, the participant learned English successfully because of the assistant of both direct and indirect strategies. In the scope of direct strategies, the participant employed memory strategies, cognitive strategies, and compensation strategies. Those three strategies were used frequently in dealing with the English language both at school and outside the school. In addition, in the scope of indirect strategies, the participant employed social strategies which undeniably gave a significant impact on her speaking proficiency.

In a similar vein, the observation conducted by the researcher showed that the participant employed both direct and indirect strategies in learning English. However, the dominant Englishlearning strategies shown by the participant were memory strategies, compensation strategies, and social strategies. The three strategies were observable during the school periods since the participant frequently applied those three strategies in the classroom. Besides, the three strategies were observed when the participant had interactions with foreign teachers. The researcher discovered that memory strategies were useful for vocabulary building and memorizing sentence structures. In terms of vocabulary building, the participant did not just memorize vocabularies. Still, the participant also put the vocabulary in written sentences and conversations with foreign teachers so that at the same time, the participant learnt the sentence structures.

Based on the findings, the researcher found out that the present study is in line with the studies conducted by Lai (2009) and Qingquan, Chatupote, $\&$ Teo (2008). The two studies revealed that successful students used a more comprehensive range of strategies. Particularly in the study conducted by Lai (2009), the subjects of the study use the six strategies in the medium frequency. In addition, the subjects reported using compensation strategies more frequently than other types of learning strategies. The specific techniques the subjects use often included guessing intelligently by using linguistic or other clues and overcoming limitations in using language by using gesture, circumlocution, or synonym.

In contrast to the previous study by Lai (2009), which revealed that among all six categories, affective strategies and memory strategies were reported as infrequently used by all students. The results showed that these students tended not to use affective strategies that helped them regulate their emotions, motivation, and attitudes while they learned and used English. Meanwhile, in the present study, the participant of the study employs memory strategies more frequently and has a better ability than other students in terms of vocabulary building. However, in a similar vein with the previous study, the participant of the 
present study employs affective strategies infrequently.

Yaacob et al. (2019) stated that in order to be successful in learning languages, in the learning strategies, a language learner must place the focus on vocabulary building rather than on memorizing grammar rules and structures. Referring to this belief, the participant in the present study had also shown more effort in vocabulary building. From the observation and interview, it was discovered that the participant enjoyed activities in the classroom which involve vocabulary games, such as hangman and categories games. Based on the observation, the participant was actively involved in the games and eager to lead the games. In addition, the school has facilitated her to improve her vocabulary. The participant had enough chances to learn new words and put the words in sentences. The school had provided every student with a book that contained vocabulary items arranged by foreign teachers. The list of vocabulary items was taken from the three English textbooks, namely Basic English, English for Communication, and Phonics. Those books were good quality books which were published by an international publisher. Hence, every student, including the participant, was required to write the meaning of the vocabulary items and put the new words in sentences. For instance, the vocabulary item was rose. The participant was obliged to find the meaning of the word rose and tried to write a sentence consisted of the word rose.

The participant also had an excellent ability to relate the lesson to her imagination. The participant could make a vocabulary item meaningful for her because the participant could imagine the real or visual object that was related to the vocabulary. For example, the participant learned the English word "solar system". When the participant knew the definition of the solar system, the participant started to imagine planets and could relate the knowledge to what the participant learned in Science Class. Another example was when the participant went to a shopping mall and found an English advertisement. The participant was intrigued to understand the advertisement. When the participant did not know vocabulary.

“... Kha, for example, I learned the words solar the meaning, the participant managed to use Google and tried to find the meaning of the words stated in the advertisement. Her curiosity enriched her

system then I imagine planets. I can use the word solar system to explain planets."

Although numerous Thai students still claim that English is a monotonous and confusing subject, the participant was interested in English subject since the participant could learn English from various sources. As a student, the participant learned a lot of English words and expressions from foreign teachers occupied to teach English at her school. However, it was undeniable that the use of technology also gave impact to her vocabulary building. The participant's vocabulary has been improving since the participant has new hobbies to watch English cartoons. The participant grew her vocabulary through English cartoons which were supported by subtitles both in English and Thai.

The cognitive strategy was also found in the participant's learning strategy. In a reading test, for instance, the participant was accustomed to answering the comprehension questions through skimming the reading text. The participant did not consider checking the meaning of each word because it was necessary to answer the question. However, in an occasion when the comprehension question required her to find out a synonym, the participant read the text slowly to find the best answer.

The participant was not only skilful at reading, but the participant was also considered as a successful student in other tests. The participant achieved excellent scores in almost all English subjects because the participant has developed habits to learn by writing summaries. The concise summary helped her a lot to understand the learning materials gathered from school. Additionally, based on the observation, the researcher found out that the participant always wrote the summaries on a thin book. Each page was mostly decorated with colorful drawings which were confirmed to be advantageous to make her interested in reading the summaries.

Despite all of the cognitive strategies possessed, the participant did not have enough time to read for fun in English. The participant attended school from Monday to Friday from 7 A.M to 5 P.M. The participant also had extra courses outside the school at the weekend. Besides, English books, English novels and English comics could be hardly found in almost all book shops in Amnat Charoen. Mostly the bookshops provided books, stories, and comics only in Thai versions. However, the participant was completed with another facility, like the internet. The participant had the chance to access the internet and social media, such as Instagram and Line so that the participant could read English text outside schools. Since the 
participant had improved her reading skill, the researcher considered that the participant should have had more efforts to practice her writing skill, mainly because the participant had the chance to express herself through the use of social media.

In terms of practicing English, The participant was considered to be the most consistent English user at school, despite the gaps of linguistic knowledge in her surroundings. The participant overcame the weaknesses by employing compensation strategies. The participant discovered that the participant could practice English with anyone, including herself. When the participant was alone, the participant could practice her English by connecting words with motions. Based on her experiences, memorizing a poem by moving around before competition started was also very helpful to overcome the nervousness and to enhance her memory. Meanwhile, when the participant needed to interact with others, moved her body and used gestures to speak English.

“... I use that because it is easier for me, teacher. I also memorize poem, or what is long by moving my body."

In daily school activities, the participant rarely found difficulties in interacting with foreign teachers. When a foreign teacher misunderstood what the participant meant, the participant used her hands to present better explanations. In addition, the participant habitually drew pictures to help her explain what the participant meant when the participant did not know the English word that the participant was going to express. For instance, in the classroom, the participant tries to speak with one of the teachers from Cameron about a Thai festival that needed candles. The participant did not know how to say candles in English; thus, the participant drew the picture of a candle. The strategy used by the participant showed that the participant never gave up, although the participant stated that sometimes the participant worried that people might not understand her.

Among various indirect strategies, the participant developed metacognitive strategies, affective strategies, and social strategies. The participant showed the metacognitive strategies through her strong will to be a good student in English class. When the teacher asked questions, the participant tried to answer the questions confidently. When the participant made mistakes, the participant recognized the mistakes, and the participant was eager to fix the errors and do the same things more carefully. The participant could find her strength in English, which was her speaking ability. Nonetheless, the participant realized that the participant still needed to practice writing. The participant stated that sometimes the participant found difficulties in writing sentences with the correct grammar.

As a primary school student, the participant was very good at managing her emotion. The participant developed appropriate affective strategies in learning English. The participant was very confident in speaking English. Hence, the participant enjoyed participating in various English competitions, such as storytelling, speech, and other projects. The participant did not just join the competitions at schools, but also in the province and national levels. In order to do all of the competitions, the participant kept the power to drive away herself from anxiety. According to her, practicing speaking in front of her classmates was a precious stepping stone to be able to speak up in front of other audiences in English competitions.

When earning a good score or winning competitions, the participant did not reward herself, but the participant was encouraged to give better performance. Everyone in her family knew that the participant loved English because the participant always shared her feelings to the family, especially to her mom. The participant did not just share her happiness, but also her anxiety every time problems during the preparation for competitions emerged. This strategy was helpful because the participant received supports psychologically. Because of her interest in English, her family supported her to practice English by giving the participant opportunities to join English courses even on the weekend to practice speaking with the foreigners. The participant was also supported to join English competitions outside Amnat Charoen Province.

The most important thing to note was that the participant was very good at speaking. The excellent speaking ability was the result of her consistency in practicing English. The vocabulary the participant earned and the speaking practice were advantageous for the enhancement of her speaking proficiency. Although the school had provided students with a day called an English day to practice English, The participant was pleased to speak English with others every day.

“... Every day is the same, if I want to speak, I speak. But I speak if there are people who understand."

From the interview, the participant also shared her opinions about people whose first language is 
English. The participant had an interest in people from a European country, namely England. The participant was not just curious about how people in England live. Still, the participant prepared herself to be able to speak English fluently so that one day the participant could visit England. In speaking English, the participant realized that sometimes the participant used the incorrect grammar, yet the participant was very convinced to speak English because the participant enjoyed it. In the school settings, the participant spoke English with foreign English teachers, Math teachers and Science teachers. However, the participant acknowledged that the participant used Thai when the participant had a conversation with a Thai teacher who taught English. The participant stated that the participant was more comfortable to speak Thai with Thai teachers, for the sake of the classmates. On the contrary, the participant was delighted to speak English with all foreign teachers at school.

\section{CONCLUSION}

To sum up, the result of the study is consistent with the findings from the majority of the previous studies (Lai, 2009; Qingquan, Chatupote, \& Teo, 2008) which suggest more frequent strategy use by more proficient learners. In the case of the participant, an indigenous English learner in Northeast Thailand, the English language has been seen as an essential part of her life. The participant loves speaking English and having interaction with foreign teachers. The participant also has been using both direct and indirect strategies. However, the most essential and dominant indirect learning strategies found in the participant is social strategies. The participant has consistency in practicing her English with foreigners.

Meanwhile, the dominant direct learning strategies the participant uses are memory strategies and compensation strategies. The participant does not just memorize vocabulary items, but the participant also summarizes learning materials so that the participant has the ability to recall the lessons well. Besides, the participant has been using compensation strategies frequently to assist her in speaking practice. The participant uses gestures to communicate well in English.

Considering that different learners may employ different strategies, more research is needed to gain a better understanding of the learning strategies of the majority of Thai learners. Besides, future researchers must consider various reasons for students choosing particular strategies in learning English.

\section{ACKNOWLEDGEMENT}

The sincerest thanks goes to the researcher's beloved student, who gladly participated in the research.

\section{REFERENCES}

Ardasheva, Y., \& Tretter, T. R. (2013). Strategy inventory for language learning-ELL student form: Testing for factorial validity. The Modern Language Journal, 97(2), 474-489. doi: 10.1111/j.1540-4781.2013.12011.x.

Bai, B., \& Guo, W. (2019). Motivation and selfregulated strategy use: Relationships to primary school students' English writing in Hong Kong. Language Teaching Research,1-22. doi: $10.1177 / 1362168819859921$.

Creswell, J.W. (2012). Educational research planning, conducting, and evaluating quantitative and qualitative research ( $4^{\text {th }}$ edn.). Boston: Pearson.

Dmitrenko, V. (2017). Language learning strategies of multilingual adults learning additional languages. International Journal of Multilingualism, 14(1), 622. doi:10.1080/14790718.2017.1258978.

Fraenkel, J. R., Wallen, N. E., \& Hyun, H. H. (2012). How to design and evaluate research in education ( $8^{\text {th }}$ edn.). New York: MacGraw-Hill.

Grubbs, S.J., Chaengploy, S., \& Worawong, K. (2009). Rajabhat and traditional universities: Institutional differences in Thai students' perceptions of English. Higher Education, 57(3), 283-298. doi:10.1007/s10734-008-9144-2.

Intachakra, S. (2004). Contrastive pragmatics and language teaching: Apologies and thanks in English and Thai*. Regional Language Centre Journal, 35(1), 37-62. doi: 10.1177/003368820403500105.

Klainin, S. (2009). Using the results from international and national assessments. Presentation at improving equity and quality of education in Thailand: An international perspective, Chiang Mai, Thailand. Retrieved from http://go.worldbank.org/K13IKDDG30.

Mazumder, Q. (2014). Student motivation and learning strategies of students from USA, China and Bangladesh. International Journal of Evaluation and Research in Education, 3(4), 205-210. doi: http://dx.doi.org/10.11591/ijere.v3i4.6288.

Minegishi, M. (2011). Description of Thai as an isolating language. Social Science Information, 50(1), 62-80. doi: 10.1177/0539018410389107.

Oxford, R.L. (1990). Language learning strategies: What every teacher should know. Boston: Heinle \& Heinle.

Oxford, R.L. (1996). Language learning strategies around the world: Cross-cultural perspective. Manoa: University of Hawaii Press.

Oxford, R.L. (2017). Teaching and researching language learning strategies: Self-regulated 


\section{Vincentia Aprilla Putri}

The English-learning strategies of an indigenous English learner in the northeast of Thailand

regulation in context ( $2^{\text {nd }}$ Ed.). New York: Routledge.

Pawlak, M. (2019). Investigating language learning strategies: Prospects, pitfalls and challenges. Language Teaching Research, 1-19. doi: $10.1177 / 1362168819876156$.

Qingquan, N., Chatupote, M., \& Teo, A. (2008). A deep look into learning strategy use by successful and unsuccessful students in the Chinese EFL learning context. RELC Journal, 39 (3), 338-358. doi: $10.1177 / 0033688208096845$.

Rao, Z. (2012). Language learning strategies and English proficiency: Interpretations from information-processing theory. The Language Learning Journal, 1-17. doi: 10.1080/09571736.2012.733886.

Seel, N.M. (Ed.). (2012). Encyclopedia of the sciences of learning. New York: Springer US. doi: 10.1007/978-1-4419-1428-6.

Seker, M. (2015). The use of self-regulation strategies by foreign language learners and its role in language achievement. Language Teaching Research, 20(5), 600-618. doi:10.1177/136216881 5578550.

Solak, E., \& Cakir, R. (2015). Language learning strategies of language e-learners in Turkey. ELearning and Digital Media, 12(1), 107-120. doi: 10.1177/2042753014558384.

Yaacob, A., Shapii, A., Alobaisy, A.S., Al-Rahmi, W.M., Al-Dheleai, Y.M., Yahaya, N., \& Alamri, M.M. (2019). Vocabulary learning strategies through secondary students at Saudi School in Malaysia, SAGE Open, 1-12. doi: $10.1177 / 2158244019835935$. 